\title{
Management of occupational asthma: cessation or reduction of exposure? \\ A systematic review of available evidence
}

\author{
O. Vandenplas*, H. Dressel\#, D. Wilken`, J. Jamart ${ }^{+}$, D. Heederik ${ }^{\S}$, P. Maestrellif \\ T. Sigsgaard ${ }^{* *}$, P. Henneberger ${ }^{\# \#}$ and X. Baur ${ }^{\star}$
}

ABSTRACT: Reduction of exposure to sensitising agents causing occupational asthma has been proposed as an alternative to total avoidance in order to minimise the adverse socio-economic impact of the condition.

The aim of this systematic review was to compare the effects of these two management options on asthma and socio-economic outcomes.

A bibliographic search was conducted to identify studies examining the outcome of workers with occupational asthma after reduction or cessation of exposure to the causal agent.

The changes in asthma symptoms and nonspecific bronchial hyperresponsiveness after reduction or cessation of exposure were described in nine and five studies, respectively. The meta-analysis of pooled data showed that a reduction of exposure was associated with a lower likelihood of improvement (OR $0.16,95 \% \mathrm{Cl} 0.03-0.91$ ) and recovery (OR $0.30,95 \% \mathrm{Cl} 0.11-0.84$ ) of asthma symptoms and a higher risk of worsening of the symptoms (OR 10.23, 95\% $\mathrm{Cl} 2.97-$ 35.28) and nonspecific bronchial hyperresponsiveness (OR 5.65, 95\% Cl 1.11-28.82), compared with complete avoidance of exposure.

This systematic review indicates that reduction of exposure cannot be routinely recommended as an alternative to cessation of exposure in the management of occupational asthma. However, further investigations are required before drawing evidence-based conclusions on the costeffectiveness of this approach.

\section{KEYWORDS: Asthma, occupational disease}

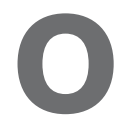
ver the past few years, work-related asthma has increasingly been recognised as a public health concern due to its high prevalence [1]; $\sim 15 \%$ of asthma in adults is attributable to the workplace environment [2]. In addition, work-related asthma significantly contributes to the global burden of asthma through its long-term respiratory health and socio-economic consequences [3, 4]. For immunologically mediated occupational asthma (OA) (i.e. "sensitizer-induced $\mathrm{OA}^{\prime}$ or "allergic OA" or "OA with a latency period"), the general therapeutic recommendation is to remove the affected workers from exposure to the causal agent $[5,6]$, since continued exposure may result in the worsening of symptoms, airway obstruction and nonspecific bronchial hyperresponsiveness (NSBHR) [7]. However, avoidance of exposure is associated with a substantial adverse socio-economic impact, because maintaining the affected worker at the same job after elimination of the hazard from the workplace or relocating of the worker to an unexposed job is often not feasible.

Recent clinical practice guidelines have acknowledged that reduction of exposure may lead to an improvement or resolution of asthma and, thus, could be considered an alternative to complete avoidance in order to minimise the socio-economic impact of OA when elimination of exposure is not feasible or unexposed jobs are not available $[5,6]$. However, the long-term effectiveness and safety of this management option remain largely uncertain [7].

The objective of this systematic review was to analyse the available data comparing the long-term health and socio-economic outcome of subjects with OA after reduction or cessation of exposure to the aetiological agent. This review aims to provide

\section{AFFILIATIONS}

${ }^{*}$ Dept of Chest Medicine, and +Scientific Support Unit, MontGodinne Hospital, Université Catholique de Louvain, Yvoir, Belgium.

\#Institute and Outpatient Clinic for Occupational, Social and Environmental Medicine, LudwigMaximilians-University, Munich, and "Institute for Occupational and Maritime Medicine, University Medical Center Hamburg-Eppendorf, Hamburg, Germany.

${ }^{\S}$ Environmental Epidemiology

Division, Institute for Risk Assessment Sciences (IRAS), University of Utrecht, Utrecht, The Netherlands.

${ }^{f}$ Dept of Environmental Medicine and Public Health, University of Padova, Padova, Italy.

**Dept of Environmental and Occupational Medicine, School of Public Health, University of Aarhus, Aarhus, Denmark.

\#\#Division of Respiratory Disease Studies, National Institute for Occupational Safety and Health, Centers for Disease Control and Prevention, Morgantown, WV, USA.

CORRESPONDENCE

0 . Vandenplas, Service de pneumologie, Cliniques Universitaires de Mont-Godinne, B-5530 Yvoir, Belgium

E-mail: olivier.vandenplas@ uclouvain.be

Received:

Nov 172010

Accepted after revision:

Feb 112011

First published online:

March 242011

Online ISSN 1399-3003 
information to physicians, patients, employers and policy makers based on the best available medical evidence.

\section{METHODS}

\section{Bibliographic search}

Publications examining the outcome of OA after reduction of exposure to the causative agent were identified through a PubMed search of articles published in any language up to December 2009. This systematic analysis was completed as part of a general review of the best available evidence on the management of work-related asthma conducted by a task force of the European Respiratory Society (ERS). The strategy used for the electronic search is available as online supplementary material. Abstracts of the retrieved papers were carefully analysed in order to identify original studies pertaining to the outcome of workers with "lower", "reduced" or "intermittent" exposures. The reference lists of relevant articles and previous systematic reviews $[7,8]$ were screened in order to identify any additional publications.

\section{Selection criteria}

The review was restricted to studies that presented a direct comparison between the outcome of workers with immunologically mediated OA who reduced their exposure and those who completely avoided exposure to the offending agent. The following exclusion criteria were applied: 1) studies of "irritantinduced asthma" and "work-exacerbated asthma"; 2) studies evaluating the clinical effects of a reduction of exposure (e.g. with personal protective equipment) during laboratory or workplace challenges; and 3) case reports, meeting abstracts and review articles. When multiple studies assessed serially over time the same, or a portion of the same, cohort of workers with $\mathrm{OA}$, the most recent report or the publication providing the most appropriate data was selected.

\section{Data collection and analysis}

Data were extracted using a standard record sheet by one reviewer and checked for completeness and accuracy by a second reviewer. The collected information pertained to the baseline demographic and clinical characteristics of the workers (sex, age, smoking status, atopy and severity of asthma); the agent(s) causing OA; the procedure used for diagnosing $\mathrm{OA}$; the duration of exposure and asthma symptoms; the nature of the interventions (reduction versus cessation of exposure); and the duration of the follow-up.

Considering the substantial heterogeneity of reported clinical and functional outcomes in follow-up studies of OA $[7,8]$, it was a priori decided to restrict the analysis to the outcome of asthma symptoms and NSBHR, which were categorised as "recovered", "improved" or "worsened", according to the criteria used in each study. Data pertaining to socio-economic outcomes (employment, loss of income, healthcare costs and quality of life) were also gathered when available. The methodological quality of the relevant studies was not formally assessed, but potential biases and confounding factors were recorded [9]. Because of the small number of available studies, no attempt was made to explicitly evaluate the effects of potential confounders, for example demographic characteristics of the subjects at baseline, atopy, smoking habits, anti-asthma treatment, molecular weight category of the agent, duration of exposure to the agent and duration of follow-up.
The meta-analysis of the pre-determined outcomes (i.e. recovery, improvement, or worsening of asthma symptoms and NSBHR) was conducted using the MetaAnalyst Beta 3.13 software [10]. In this meta-analysis, "recovery" was considered a subcategory of "improvement" and was analysed either separately or combined with the "improvement" group. The heterogeneity within the results of the studies was assessed using the Cochran $Q$ test and was considered significant when the $\mathrm{p}$-value was $<0.10$. The results were summarised as the odds ratios and $95 \%$ confidence intervals for each outcome among workers who reduced exposure, compared with those who avoided exposure, using either a fixed-effect or a random-effect model according to the presence of significant heterogeneity. The pooled prevalence estimates of each outcome after reduction or cessation of exposure were computed using a random-effect model. The draft evidence report was reviewed by all members of the ERS task force on the management of work-related asthma.

\section{RESULTS}

\section{Characteristics of included studies}

The bibliographic search identified 114 publications, from which we selected 32 original studies pertaining to the outcome of "reduced exposure". Of these 32 publications, 10 studies met the inclusion criteria and were included in the analysis (table 1) [11-20]. 22 articles were excluded for the following reasons: 1) lack of a comparison group of workers who avoided exposure [21-27]; 2) comparison with asymptomatic workers who remained exposed to the offending agent [28]; 3) serial assessments of the same or a portion of the same cohort of workers with OA due to red cedar dust [13, 29-33], isocyanates [34] or persulphate salts [35]; 4) failure to provide appropriate data on the outcomes of patients who had "reduced exposure" [36-40]; and 5) single case report [41].

Eight of the 10 selected publications involved a longitudinal follow-up of patients recruited from specialised clinics [11-16, $18,20]$, although the mode of selection of the participants and their participation rate were not clearly stated in four studies [12-15]. Two studies were retrospective surveys of patients whose functional parameters were not assessed before environmental interventions [17, 19]. The studies included 478 patients with OA (median (interquartile range) sample size of the studies 28 (22-64)); 186 patients (18 (8-26) per study) had reduced exposure and 292 (12 (7-26) per study) had avoided exposure to the causal agent. The most commonly identified causal agents (seven of 10 publications) were low molecular weight agents, including isocyanates [12, 15, 16], colophony [11], red cedar dust [13], platinum salts [17] and persulphate salts [20], while only two studies involved a high molecular weight agent (i.e. natural rubber latex) [18, 19], and one study evaluated patients with OA caused by various agents, of which $90 \%$ were low molecular weight agents [14]. The diagnosis of OA was established by a positive specific inhalation test in seven studies $[11,13-16,18,20]$ or the combination of a positive immunological test with functional assessments (i.e. specific inhalation challenge in the laboratory and/or monitoring of peak expiratory flow rates at work) $[12,17]$, or with a consistent clinical history [19].

The interventions aimed at reducing exposure are summarised in table 1; none of the studies provided quantitative assessments of exposure before or after the intervention. The baseline 


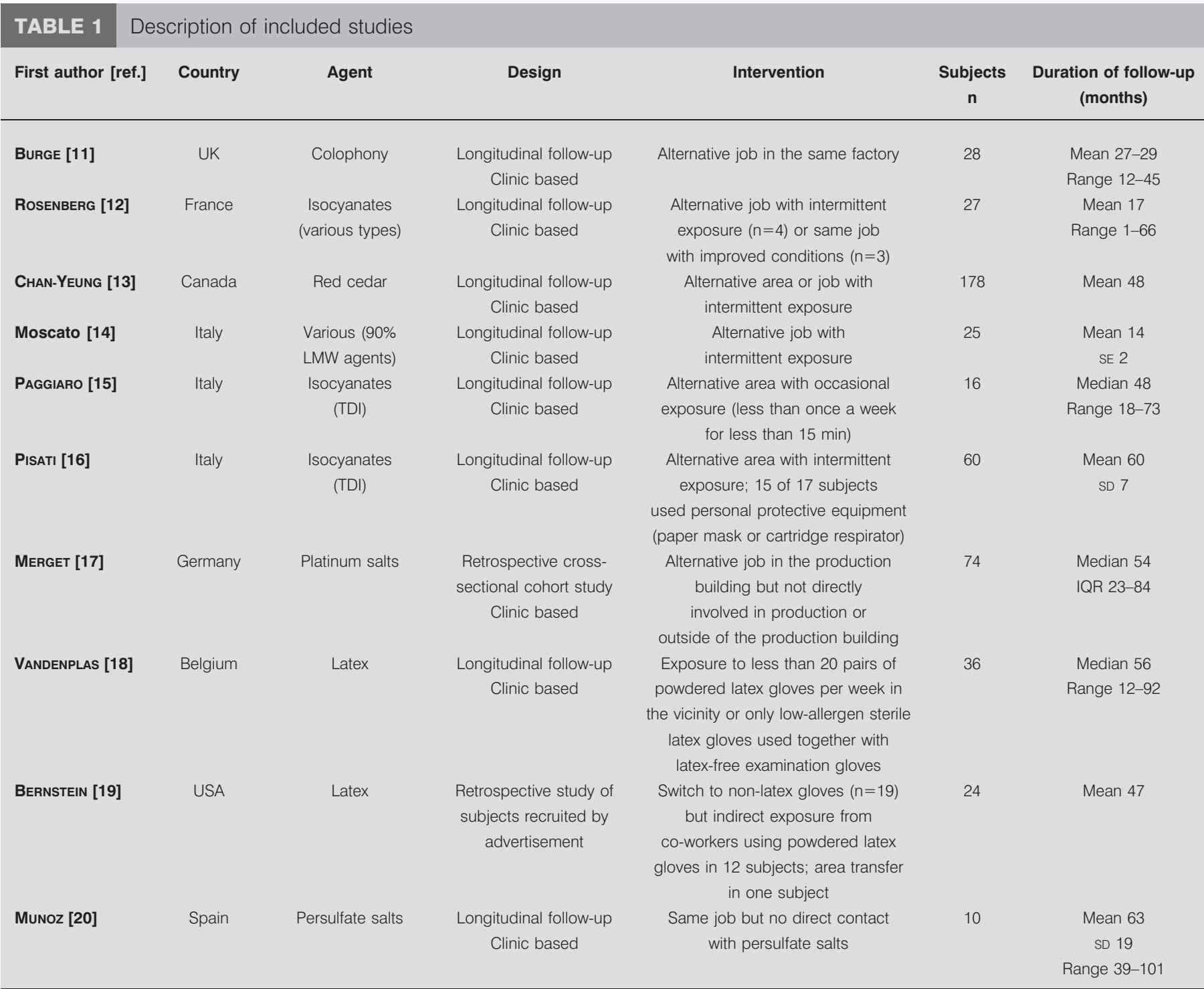

LMW: low molecular weight; TDI: toluene diisocyanate; IQR: interquartile range.

characteristics of the workers who reduced exposure were compared to those of the workers who ceased exposure in five of the eight prospective follow-up studies [13, 15, 16, 18]. These comparisons provided inconsistent findings across the studies; reduction of exposure being associated either with a lower baseline forced expiratory volume in $1 \mathrm{~s}$ (FEV1) [11], or a younger age and a shorter duration of exposure before intervention [15], or an older age and a longer duration of exposure [16], or less frequent treatment with inhaled corticosteroids [18], or a higher proportion of atopics [13]. The median or mean follow-up periods ranged from 14 to 63 months. Five studies did not compare the duration of follow-up in workers who reduced and those who avoided exposure [12, 14, 16, 17, 19]. The duration of the follow-up did not differ among the two groups in four studies [11,13,15,18], while it was longer for the patients with reduced exposure in one study [20]. Changes in asthma medications during the follow-up period were described in four of 10 studies [15, 16, 18, 20], and only one study reported on the changes in smoking habits [16].

\section{Effects of interventions on asthma symptoms}

Nine publications described the outcome of asthma symptoms after reduction (179 patients) or cessation (283 patients) of exposure using the following categorisation: complete resolution (nine studies, 462 patients), improvement (five studies, 164 patients), or worsening (five studies, 119 patients) (table 2) [1114, 16-20]. Most (six out of nine) of these studies relied on a qualitative assessment of the changes in asthma symptoms, while only three studies used a quantified symptom score [16, 18]. PISATI et al. [16] analysed the changes in asthma status using a score that combined symptoms, medications, and the changes in FEV1 and NSBHR (table 2). The study by VANDENPLAS et al. [18] reported the median values of an asthma severity score that was derived from the frequency of asthma symptoms, the need for asthma medications, and hospital admissions, but also provided the proportion of patients who recovered from their asthma, as defined by the absence of symptoms and anti-asthma medication. MuNOz et al. [20] graded asthma severity according to the criteria proposed by the Global Initiative for Asthma guidelines. 
TABLE 2 Reported outcome of asthma symptoms

\begin{tabular}{|c|c|c|c|c|c|c|c|}
\hline \multirow[t]{2}{*}{ First author [ref.] } & \multirow[t]{2}{*}{ Agent } & \multicolumn{3}{|c|}{ Reduction of exposure } & \multicolumn{3}{|c|}{ Cessation of exposure } \\
\hline & & Recovered & Improved $^{\#}$ & Worse & Recovered & Improved $^{\#}$ & Worse \\
\hline BURGE [11] & Colophony & $1 / 8$ & $6 / 8$ & NA & $4 / 20$ & $20 / 20$ & $0 / 20$ \\
\hline ROSENBERG [12] & Isocyanates & $0 / 7$ & $4 / 7$ & $2 / 7$ & $10 / 20$ & $14 / 20$ & NA \\
\hline Chan-Yeung [13] & Red cedar & $0 / 42$ & NA & NA & $55 / 136$ & NA & NA \\
\hline Merget [17] & Platinum salts & $25 / 55$ & NA & NA & $10 / 19$ & NA & NA \\
\hline VANDENPLAS [18] & Latex & $4 / 20$ & NA & NA & $3 / 16$ & NA & NA \\
\hline BERNSTEIN [19] & Latex & $20 / 20$ & $20 / 20$ & $0 / 20$ & $4 / 4$ & $4 / 4$ & $0 / 4$ \\
\hline MunOz [20] & Persulfate salts & $0 / 3$ & NA & $0 / 3$ & $2 / 7$ & NA & $0 / 7$ \\
\hline \multirow[t]{2}{*}{ Pooled estimate } & & $50 / 179$ & $34 / 59$ & $15 / 54$ & $109 / 283$ & $78 / 105$ & $5 / 92$ \\
\hline & & $17.6 \%$ & $60.1 \%$ & $20.6 \%$ & $38.2 \%$ & $81.4 \%$ & $8.8 \%$ \\
\hline
\end{tabular}

The meta-analysis of the pooled data (table 3) showed that the reduction of exposure was associated with a lower likelihood of improvement (OR 0.16, 95\% CI 0.03-0.91) and recovery (OR $0.30,95 \%$ CI $0.11-0.84$ ) from asthma symptoms and a higher risk of symptom worsening (OR 10.23, 95\% CI 2.97-35.28), compared with avoidance of exposure (fig. 1).

\section{Effects of interventions on NSBHR}

Five studies evaluated the changes in NSBHR after reduction (44 patients) or cessation (66 patients) of exposure (table 4) [11, $12,15,18,20]$. The level of NSBHR was assessed using various methods; the five publications stated the threshold concentration or dose of a pharmacological agent (i.e. acetylcholine, histamine or methacholine) to achieve a specified bronchial response that was considered as reflecting a level of NSBHR in the asthmatic range. Recovery from NSBHR was considered when these threshold concentrations or doses exceeded the cut-off values for asthma at the follow-up assessment (table 4). The magnitude of the change in the concentration or dose of pharmacological agent at follow-up assessment that was considered as being significant was not clearly stated in two studies and was assigned a threshold value of one doubling concentration or dose [11, 12].

The meta-analysis of changes in NSBHR (table 3) revealed that reduction of exposure was associated with a significantly higher risk of NSBHR worsening (OR 5.65, 95\% CI 1.11-28.82), compared with cessation of exposure (fig. 2).

TABLE 3 Meta-analysis of the impact of cessation and reduction of exposure on asthma symptoms and nonspecific bronchial hyperresponsiveness (NSBHR)

Outcome
Test for heterogeneity
Reduction versus cessation of exposure to the causal agent
Fixed effect model

OR $(95 \% \mathrm{Cl})$
Random effect model OR $(95 \% \mathrm{Cl})$

$\begin{array}{ll}\text { Asthma symptoms } & \\ \text { Recovery } & \mathrm{p}=0.037 \\ \text { Improvement } & \mathrm{p}=0.001 \\ \text { Worsening } & \mathrm{p}=0.114 \\ \text { NSBHR } & \\ \text { Recovery } & \mathrm{p}=0.304 \\ \text { Improvement } & \mathrm{p}=0.050 \\ \text { Worsening } & \mathrm{p}=0.884\end{array}$

NC: not computed due to the presence of significant heterogeneity 
a) Symptom recovery

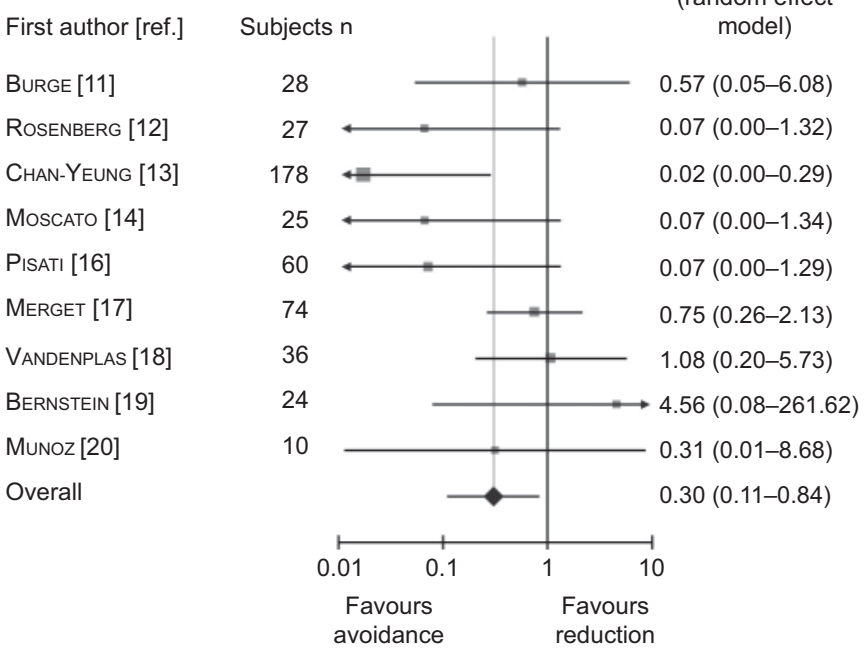

b) Symptom improvement

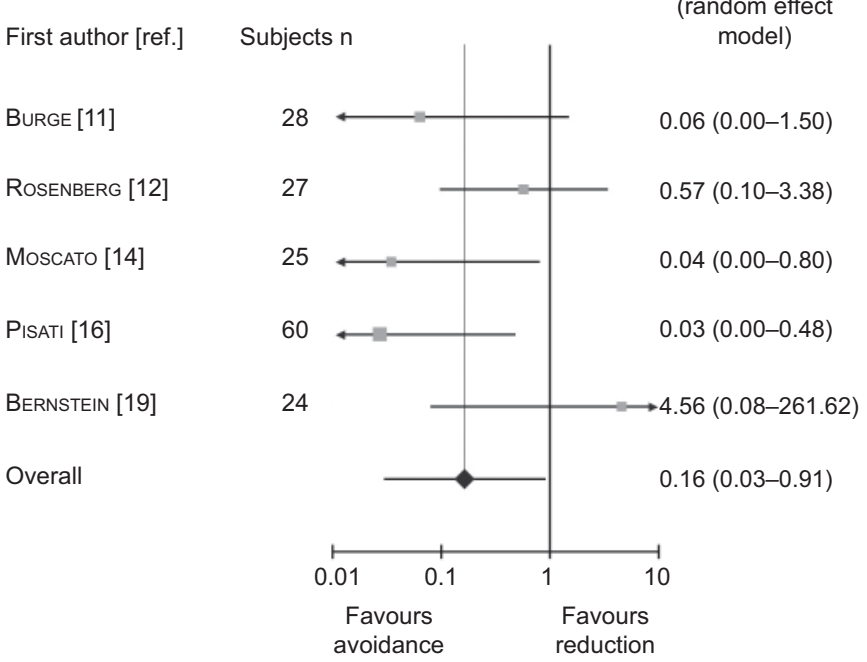

c) Symptom worsening

OR $(95 \% \mathrm{Cl})$ (fixed effect model)

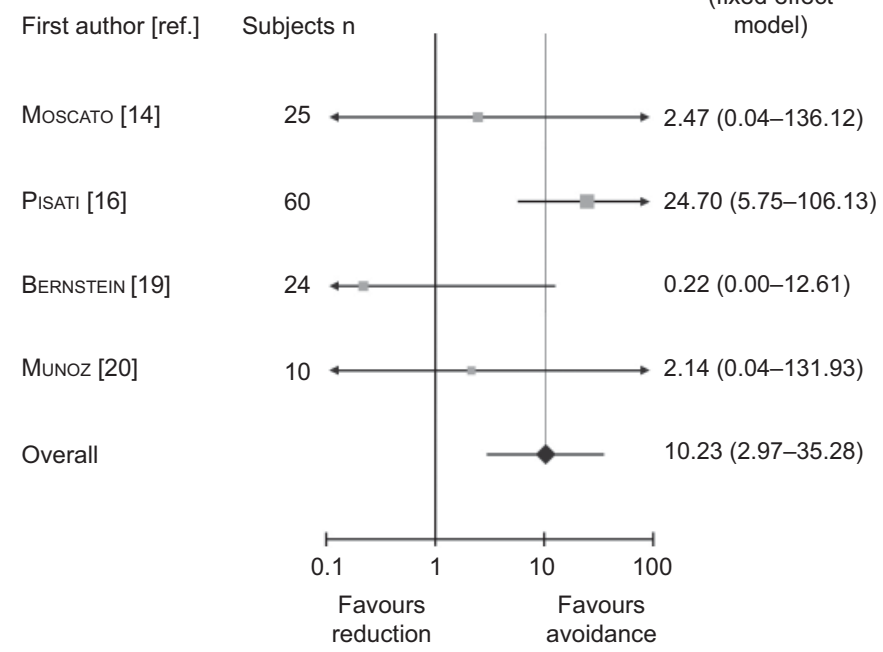

FIGURE 1. Forest plot of the comparison of the outcome of asthma symptoms: a) recovery, b) improvement and c) worsening.

\section{Socio-economic outcomes}

Five of the 10 publications [11, 14, 15, 18, 19] provided some socio-economic information, but the employment status at the follow-up visit was clearly stated in only two studies of workers with OA caused by colophony [11] and natural rubber latex gloves [18]. These studies revealed that the proportion of currently employed workers was significantly higher among those who reduced exposure (eight out of eight in colophonyinduced OA and 20 out of 20 in latex-induced OA) as compared to those who avoided exposure (seven out of 20 in colophony-induced OA $(\mathrm{p}=0.004)$ and nine out of 16 in latexinduced OA $(\mathrm{p}=0.003))$. The study by VANDENPLAS et al. [18] reported that a major loss of income was more frequent in subjects with latex-induced OA who ceased exposure to latex (nine out of 16) than in subjects who remained exposed to reduced levels of latex (three out of 20; $\mathrm{p}=0.023$ ). The median (interquartile range) actual reduction in earnings was $20 \%(0$ $51 \%$ ) from the initial value after avoidance of exposure and $0 \%$ $(0-16 \%)(p=0.038)$ after the reduction of exposure. Asthmarelated quality of life at the follow-up visit did not differ between the two groups.

\section{DISCUSSION}

\section{Findings}

This meta-analysis of 10 studies including 478 subjects with OA showed that reducing exposure to the causal agent was associated with a lower likelihood of improvement and recovery of asthma symptoms and a higher risk of worsening of symptoms and NSBHR, compared with complete avoidance of exposure. These findings do not provide sufficient evidence for using exposure reduction as a management option in patients with OA and they further support the statements that reduction of exposure "is not always effective" [5] and that "there is little evidence for using this approach" [6]. The systematic review on the management of $\mathrm{OA}$ by $\mathrm{BEACH}$ et al. [7] examined the outcome of symptoms $[11,12,17,18,22,23,26$, $27,41]$, medications [11, 12, 18, 23, 35], FEV1 [11, 12, 18] and NSBHR $[11,12,18]$ after the reduction of exposure in studies published up to 2004. The authors concluded that the majority of the studies on subjects who reduced exposure reported the following: some improvement in asthma symptoms; no clear pattern of changes in medication use; an improvement in FEV1 over time in less than half of the studies; and that there were insufficient data (improvement in one of three studies) to draw conclusions about the changes in NSBHR. In contrast to BEACH et al. [7], we deliberately opted to restrict our review to publications that allowed for a direct comparison between those workers who reduced and those who avoided exposure to the offending agent. Moreover, we analysed the changes in symptoms and NSBHR after the interventions in a simple, categorical manner (i.e. recovery, improvement and worsening) as proposed by RACHIOTIS et al. [8] in their systematic review of the outcome of OA after avoidance of exposure. Six $[22,23,26,27,35,41]$ of the 10 studies $[11,12,17,18,22,23,26$, $27,35,41]$ on workers with reduced exposure in the review by BEACH et al. [7] were excluded from our analysis because they did not match our pre-defined inclusion criteria. However, we analysed six studies $[13-16,19,20]$ that were not included in the review of BEACH et al. [7]. Noticeably, the cohorts of workers who avoided exposure that were selected in our review did not differ from those examined by RACHIOTIS et al. [8]. The rates of 
TABLE 4 Reported outcome of nonspecific bronchial hyperresponsiveness (NSBHR)

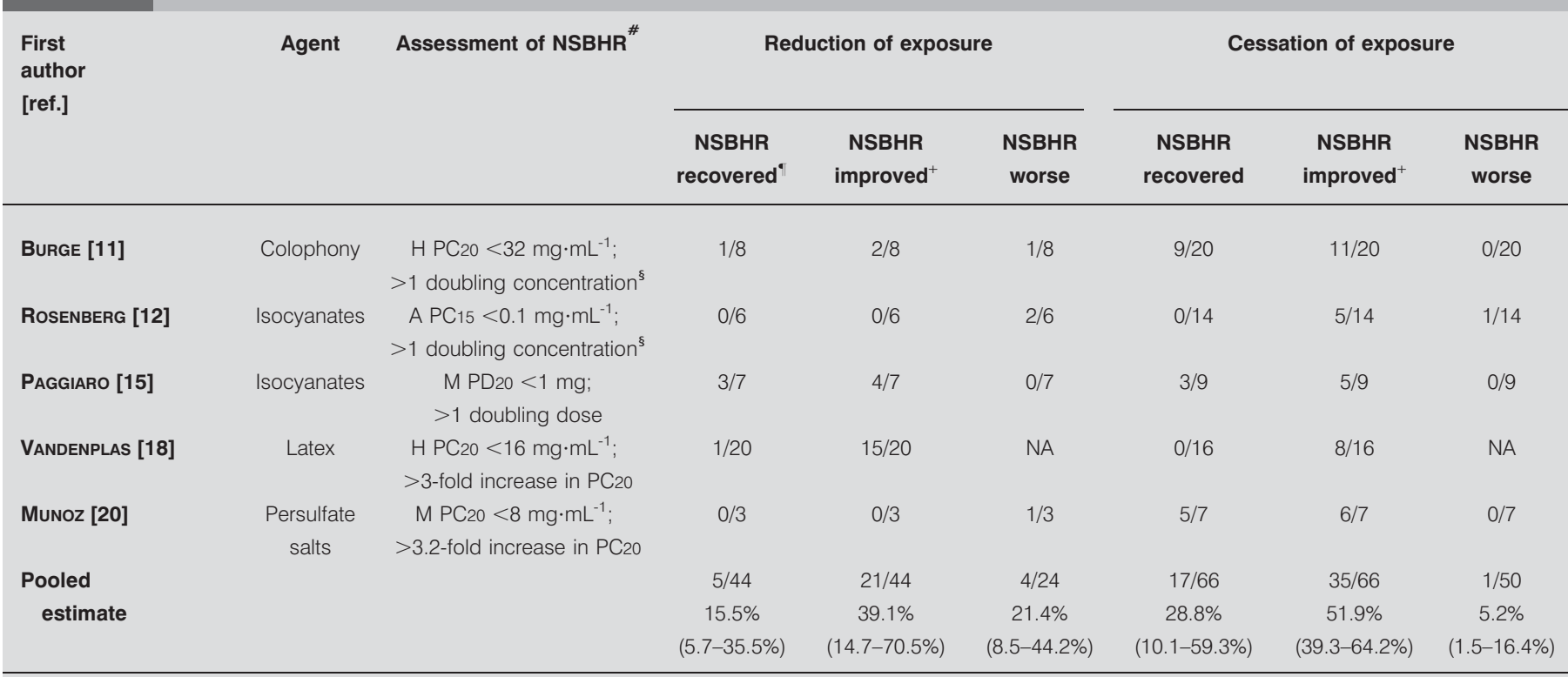

$\mathrm{H}$ : histamine; PC/PD15/20: concentration or dose of the pharmacological agent inducing a 15 or $20 \%$ fall in forced expiratory volume in $1 \mathrm{~s}$; $\mathrm{A}$ : acetylcholine; $\mathrm{M}$ : methacholine; NA: not available. ${ }^{\#}$ : cut-off values for asthma and significant improvement; ": recovery from NSBHR was considered when the concentration or dose of the pharmacological agent inducing the specified functional change exceeded the cut-off value for asthma at the follow-up assessment; ${ }^{+}$: subjects with improved NSBHR, including those who recovered; ${ }^{\text {s: }}$ threshold value for a significant change assigned by the authors.

symptoms and NSBHR recovery after cessation of exposure that were found in our review $(38 \%, 95 \%$ CI $29-48 \%$, and $29 \%$, 95\% CI 10-59\%, respectively) were similar to those reported by RACHIOTIS et al. [8] (32\%, 95\% CI 26-38\%, and $27 \%, 95 \%$ CI $21-34 \%)$.

Very few studies provided analysable information on socioeconomic outcomes. Two studies found that the reduction of exposure resulted in a lower rate of unemployment than the avoidance of exposure [11, 18]. Accordingly, it remains uncertain whether reducing exposure results in a lower socio-economic impact than complete avoidance of exposure.

\section{Limitations}

A number of methodological weaknesses of this systematic review should be carefully considered before drawing definitive conclusions for clinical practice. First, available studies have a high, though unquantifiable, potential for selection bias since all publications were observational follow-up studies where the rationale for the intervention decision (i.e. reduction versus avoidance of exposure) was largely unknown. Noticeably, the proportion of subjects who avoided exposure was markedly higher compared with those who reduced exposure in most studies involving low molecular weight agents (i.e. 2.3 to 3.2-fold higher) $[11-14,16,20]$. By contrast, reduction of exposure was a more common intervention than avoidance (i.e. 1.2 to 5.0 -fold more common) only for workers with OA due to latex $[18,19]$ and platinum [17]. This suggests that the outcome of reducing exposure has been mainly investigated in some specific work environments and that the observed effects may not be extrapolated to other settings. In addition, it is possible to speculate that subjects with more severe asthma had the tendency to avoid rather than reduce exposure to the causal agent. In the five studies comparing the baseline clinical data of the subjects, there was no clear indication that those who reduced exposure to the causal agent had less severe asthma than those who avoided exposure [11, 13, 15, 16, 18], with the exception of the study by VANDENPLAS et al. [18], in which the subjects who ceased exposure to latex allergens were more frequently treated with inhaled corticosteroids than those who reduced exposure. BEACH et al. [7] compared the baseline FEV1 in cohorts of subjects with OA who continued or avoided exposure, and concluded that lung function at diagnosis was not associated with exposure status during follow-up. However, it should be acknowledged that prospective randomised controlled trials of the effectiveness of various management approaches will never be conducted due to ethical considerations.

Secondly, information regarding "baseline" workplace exposures, the interventions taken to reduce exposures, and the effectiveness of such interventions, was very limited. None of the included studies relied on quantitative exposure assessments to document reduction of exposure, although quantifying the reduction of exposure may be difficult owing to the day-today variability in the level of exposure in most workplaces. Nevertheless, the interventions aimed at reducing exposure to asthmagens, such as the use of personal protective equipment, engineering changes to the workplace or the relocation of the worker to area or job with decreased exposure, were, in most cases, not clearly described. Therefore, it was not possible to take into account the actual magnitude of the reduction in the level of exposure achieved in each cohort. In addition, none of the interventions were based on an a priori definition of what should be a biologically relevant reduction of exposure. 
a) NSBHR recovery

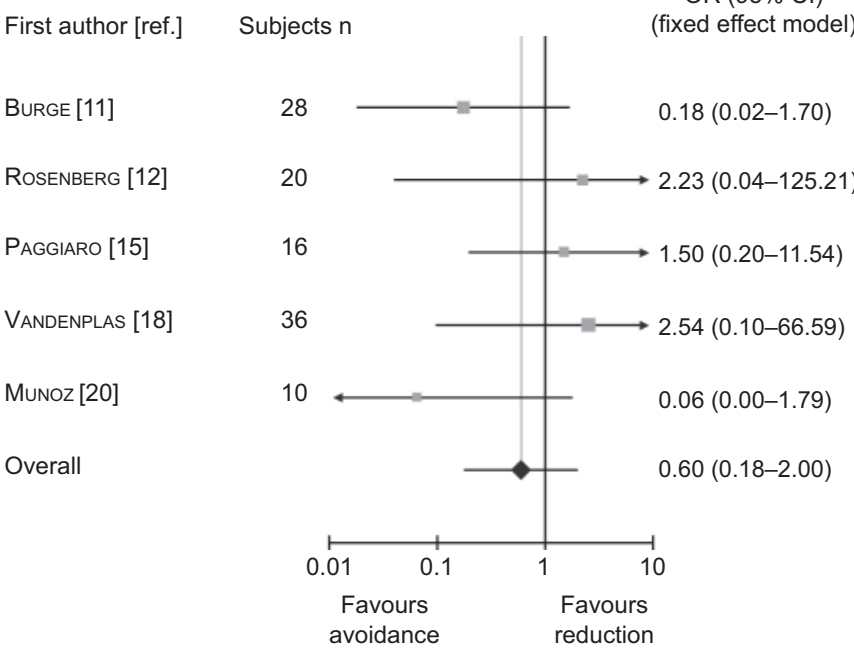

b) NSBHR improvement

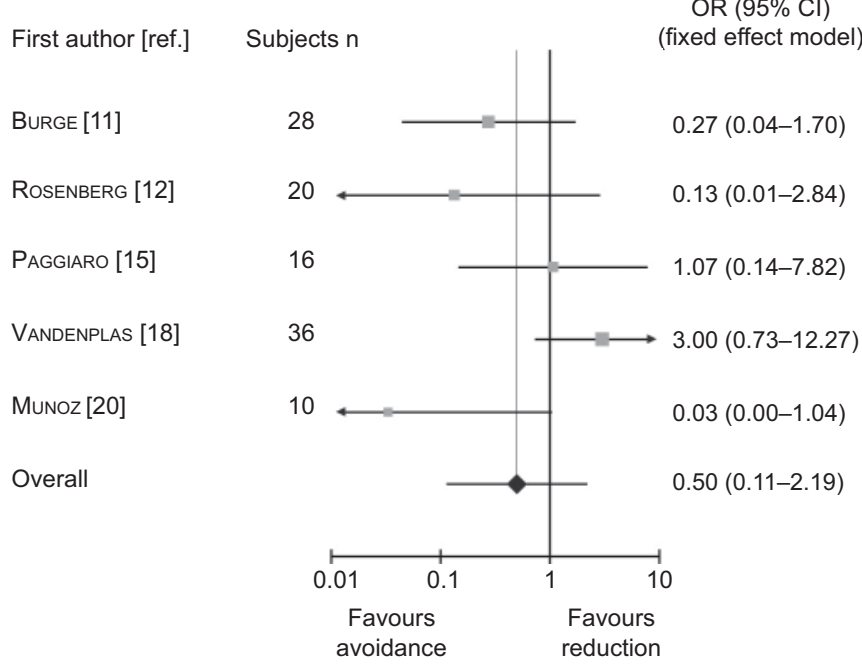

c) NSBHR worsening

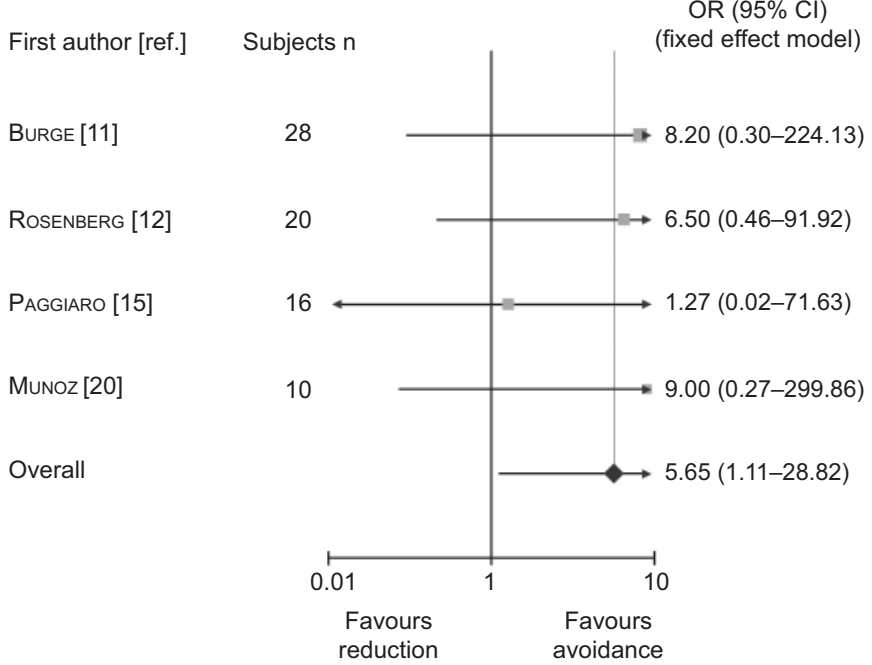

FIGURE 2. Forest plot of the comparison of the outcome of nonspecific bronchial hyperresponsiveness (NSBHR): a) recovery, b) improvement and c) worsening.
Thirdly, significant between-study heterogeneity was observed for both studied outcomes, with the exception of symptom worsening and changes in the level of NSBHR. Included studies were very heterogeneous in their sample size, methods of assessment and outcome reporting. Therefore, it was not possible to control for potential confounders, such as atopic status, history of asthma pre-existing to the causal exposure, the duration of symptoms before the intervention, and changes in smoking habits and asthma treatment during the followup period. There was also considerable within-study heterogeneity since available studies included workers with very different types of exposure to the same agent, for instance workers exposed to various types of isocyanates in different industries $[12,16]$. In addition, most of the studies did not use standardised, validated instruments for assessing the severity or control of asthma symptoms and their impact on quality of life.

Finally, the major limitation of this review relates to the low generalisability of its findings. Thus, it was not possible to separately analyse the outcome of the interventions according to the nature of the causal agents since most of the available publications (i.e. eight out of 10 cohorts) involved populations exposed to low molecular weight agents. Furthermore, studies pertaining to high molecular weight agents were restricted to natural rubber latex gloves. For instance, a large majority of the studies reporting on the improvement of asthma symptoms (fig. 1b) $[11,12,14,16,19,20]$ and the worsening of symptoms $[14,16,19,20]$ and NSBHR $[11,12,15,20]$ assessed populations with $\mathrm{OA}$ due to low molecular weight agents, mainly isocyanates (figs $1 \mathrm{c}$ and $2 \mathrm{c}$ ).

\section{Conclusions}

This systematic review of available evidence found that reduction of exposure to agents causing OA is associated with in a less beneficial effect on asthma outcome than complete avoidance. These findings indicate that the reduction of exposure cannot be routinely advocated as an alternative to the cessation of exposure. However, the limited quality of available studies prevents us from drawing definitive conclusions on the effectiveness and safety of reducing exposure to occupational asthmagens. Moreover, the data are not sufficient for a comparison of the socio-economic consequences of these two management approaches to be made. There is a clear need for further investigation of the cost-effectiveness of the different management options of OA caused by various agents, through prospective and large-scale studies based on outcomes that have been validated for the evaluation of asthma and quantitative evaluation of interventions aimed at reducing exposure.

\section{SUPPORT STATEMENT}

This document presents the results of a systematic review on this specific issue, which has been completed as part of a larger review conducted by the ERS task force on the management of work-related asthma. This paper is not considered part of the official task force report; the full, official report will be presented in future issues of the European Respiratory Journal and the European Respiratory Review. The work of the task force on the management of work-related asthma was funded by the European Respiratory Society. The findings and conclusions in this report are those of the authors and do not necessarily represent the views of the National Institute for Occupational Safety and Health. 


\section{STATEMENT OF INTEREST}

None declared.

\section{REFERENCES}

1 Bousquet J, Kiley J, Bateman ED, et al. Prioritised research agenda for prevention and control of chronic respiratory diseases. Eur Respir J 2010; 36: 995-1001.

2 Toren K, Blanc PD. Asthma caused by occupational exposures is common - a systematic analysis of estimates of the populationattributable fraction. BMC Pulm Med 2009; 9: 7.

3 Vandenplas O, Toren K, Blanc PD. Health and socioeconomic impact of work-related asthma. Eur Respir J 2003; 22: 689-697.

4 Miedinger D, Malo JL, Ghezzo H, et al. Factors influencing duration of exposure with symptoms and costs of occupational asthma. Eur Respir J 2010; 36: 728-734.

5 Nicholson PJ, Cullinan P, Taylor AJ, et al. Evidence based guidelines for the prevention, identification, and management of occupational asthma. Occup Environ Med 2005; 62: 290-299.

6 Tarlo SM, Balmes J, Balkissoon R, et al. Diagnosis and management of work-related asthma: American College Of Chest Physicians Consensus Statement. Chest 2008; 134: Suppl. 3, 1S-41S.

7 Beach J, Rowe BH, Blitz S, et al. Diagnosis and Management of Occupational Asthma. Evidence Report/Technology Assessment Number 129. AHRQ Publication No 06-E003-2. Rockville, US Department of Health and Human Services, Agency for Healthcare Research and Quality, 2005. Available from: www.ahrq.gov

8 Rachiotis G, Savani R, Brant A, et al. Outcome of occupational asthma after cessation of exposure: a systematic review. Thorax 2007; 62: 147-152.

9 Nicholson PJ. How to undertake a systematic review in an occupational setting. Occup Environ Med 2007; 64: 353-358.

10 Wallace BC, Schmid CH, Lau J, et al. Meta-Analyst: software for meta-analysis of binary, continuous and diagnostic data. BMC Med Res Methodol 2009; 9: 80

11 Burge PS. Occupational asthma in electronics workers caused by colophony fumes: follow-up of affected workers. Thorax 1982; 37: 348-353.

12 Rosenberg N, Garnier R, Rousselin X, et al. Clinical and socioprofessional fate of isocyanate-induced asthma. Clin Allergy 1987; 17: 55-61.

13 Chan-Yeung M, MacLean L, Paggiaro PL. Follow-up study of 232 patients with occupational asthma caused by western red cedar (Thuja plicata). J Allergy Clin Immunol 1987; 79: 792-796.

14 Moscato G, Bertoletti R, Biscaldi G, et al. Occupational asthma: fate and management after the diagnosis. G Ital Med Lav 1993; 15: 27-31.

15 Paggiaro PL, Vagaggini B, Dente FL, et al. Bronchial hyperresponsiveness and toluene diisocyanate. Long-term change in sensitized asthmatic subjects. Chest 1993; 103: 1123-1128.

16 Pisati G, Baruffini A, Zedda S. Toluene diisocyanate induced asthma: outcome according to persistence or cessation of exposure. Br J Ind Med 1993; 50: 60-64.

17 Merget R, Schulte A, Gebler A, et al. Outcome of occupational asthma due to platinum salts after transferral to low-exposure areas. Int Arch Occup Environ Health 1999; 72: 33-39.

18 Vandenplas O, Jamart J, Delwiche JP, et al. Occupational asthma caused by natural rubber latex: outcome according to cessation or reduction of exposure. J Allergy Clin Immunol 2002; 109: 125-130.

19 Bernstein DI, Karnani R, Biagini RE, et al. Clinical and occupational outcomes in health care workers with natural rubber latex allergy. Ann Allergy Asthma Immunol 2003; 90: 209-213.

20 Munoz X, Gomez-Olles S, Cruz MJ, et al. Evolución de la hiperrespuesta bronquial en pacientes con asma ocupacional por exposición a sales de persulfato. [Course of bronchial hyperresponsiveness in patients with occupational asthma caused by exposure to persulfate salts.] Arch Bronconeumol 2008; 44: 140-145.
21 Wang JD, Huang PH, Lin JM, et al. Occupational asthma due to toluene diisocyanate among velcro-like tape manufacturers. Am J Ind Med 1988; 14: 73-78.

22 O'Donnell TV, Welford B, Coleman ED. Potroom asthma: New Zealand experience and follow-up. Am J Ind Med 1989; 15: 43-49.

23 Banks DE, Rando RJ, Barkman HW Jr. Persistence of toluene diisocyanate-induced asthma despite negligible workplace exposures. Chest 1990; 97: 121-125.

24 Grammer LC, Shaughnessy MA, Henderson J, et al. A clinical and immunologic study of workers with trimellitic-anhydride-induced immunologic lung disease after transfer to low exposure jobs. Am Rev Respir Dis 1993; 148: 54-57.

25 Douglas JD, McSharry C, Blaikie L, et al. Occupational asthma caused by automated salmon processing. Lancet 1995; 346: 737-740.

26 Smith TA, Patton J. Health surveillance in milling, baking and other food manufacturing operations - five years' experience. Occup Med (Lond) 1999; 49: 147-153.

27 Grammer LC, Shaughnessy MA, Kenamore BD. Clinical and immunologic outcome of 42 individuals with trimellitic anhydride-induced immunologic lung disease after transfer to low exposure. Allergy Asthma Proc 2000; 21: 355-359.

28 Soyseth V, Kongerud J, Aalen OO, et al. Bronchial responsiveness decreases in relocated aluminum potroom workers compared with workers who continue their potroom exposure. Int Arch Occup Environ Health 1995; 67: 53-57.

29 Chan-Yeung M. Fate of occupational asthma. A follow-up study of patients with occupational asthma due to Western Red Cedar (Thuja plicata). Am Rev Respir Dis 1977; 116: 1023-1029.

30 Chan-Yeung M, Lam S, Koener S. Clinical features and natural history of occupational asthma due to western red cedar (Thuja plicata). Am J Med 1982; 72: 411-415.

31 Côté J, Kennedy S, Chan-Yeung M. Outcome of patients with cedar asthma with continuous exposure. Am Rev Respir Dis 1990; 141: 373-376.

32 Marabini A, Dimich-Ward H, Kwan SY, et al. Clinical and socioeconomic features of subjects with red cedar asthma. A follow-up study. Chest 1993; 104: 821-824.

33 Lin FJ, Dimich-Ward H, Chan-Yeung M. Longitudinal decline in lung function in patients with occupational asthma due to western red cedar. Occup Environ Med 1996; 53: 753-756.

34 Paggiaro PL, Loi AM, Rossi O, et al. Follow-up study of patients with respiratory disease due to toluene diisocyanate (TDI). Clin Allergy 1984; 14: 463-469.

35 Munoz X, Cruz MJ, Orriols R, et al. Occupational asthma due to persulfate salts: diagnosis and follow-up. Chest 2003; 123: 2124-2129.

36 Moscato G, Dellabianca A, Perfetti L, et al. Occupational asthma: a longitudinal study on the clinical and socioeconomic outcome after diagnosis. Chest 1999; 115: 249-256.

37 Piirila PL, Nordman H, Keskinen HM, et al. Long-term follow-up of hexamethylene diisocyanate-, diphenylmethane diisocyanate-, and toluene diisocyanate-induced asthma. Am J Respir Crit Care Med 2000; 162: 516-522.

38 De Zotti R, Muran A, Negro C. Follow up dei sintomi allergici in un gruppo di operatori sanitari sensibilizzati al lattice. [Follow-up of allergic symptoms in a group of health workers sensitized to latex.] Med Lav 2000; 91: 53-60.

39 Visentin A, Fedeli U, Zanetti C, et al. Follow up dell'asma professionale da lattice. [Follow-up of latex-induced occupational asthma]. G Ital Med Lav Ergon 2003; 25: Suppl., 190-191.

40 Bussetti A, Folletti I, Armadori M, et al. L'allergia al lattice tra dipendenti dell'ospedale di terni: follow-up dei soggetti sintomatici. [Latex allergy in hospital workers-follow-up of symptomatic subjects]. G Ital Med Lav Ergon 2007; 29: 418-420.

41 Harries MG, Burge PS, Samson $M$, et al. Isocyanate asthma: respiratory symptoms due to 1,5-naphthylene di-isocyanate. Thorax 1979; 34: 762-766. 